\title{
Surface modification and micromechanical properties of jute fiber mat reinforced polypropylene composites
}

\author{
X. Y. Liu*, G. C. Dai \\ State-Key Laboratory of Chemical Engineering, East China University of Science and Technology, 130 Meilong Road, \\ Shanghai 200237, P. R. China
}

Received 13 March 2007; accepted in revised form 23 April 2007

\begin{abstract}
A new treating method using sodium hydroxide ( $\mathrm{NaOH})$ and Maleic anhydride-grafted polypropylene (MPP) emulsion was introduced to treat jute fiber mat in order to enhance the performance of jute/polypropylene (PP) composite prepared by film stacking method. The surface modifications of jute fiber mat have been found to be very effective in improving the fiber-matrix adhesion. It was shown that treatments changed not only the surface topography but also the distribution of diameter and strength for the jute fibers, which was analyzed by using a two-parameter Weibull distribution model. Consequently, the interfacial shear strength, flexural and tensile strength of the composites all increased, but the impact strength decreased slightly. These results have demonstrated a new approach to use natural materials to enhance the mechanical performances of composites.
\end{abstract}

Keywords: mechanical properties, jute fiber mat, polypropylene, surface modification, distribution

\section{Introduction}

Ecological concern has resulted in a renewed interest in natural materials for their recyclability, light weight and non pollution. Important issues such as recyclability and environmental safety need to be addressed when new materials and products are introduced. Lignocellulosic natural fibers such as flax, hemp, sisal and jute are an interesting, environmentally friendly alternative to the use of glass fibers as reinforcement in engineering composites because of the benefits that these fibers provide over conventional reinforcement materials, and the development of natural fiber composites has been a subject of interest for the past few years [1-4]. These fibers are renewable, nonabrasive, and can be incinerated for energy recovery since they possess a good calorific value and cause little concern in terms of health and safety during handling of fiber products. In addition, they exhibit excellent mechanical properties, low density and are cheap. This good environmental friendly feature makes the materials very popular in engineering markets such as the automotive [5-8] and construction industry $[9,10]$.

There are several reports about the use of jute as reinforcing fibers for thermosets [11-13] and thermoplastics $[14,15]$. The studies of jute fiber composites were carried out mostly in India in early years and jute fiber reinforced thermosets had been the focus of studies. In recent years, natural fiber reinforced thermoplastics were receiving more and more attention because of issues of environmental protection. Fiber treatment and interfacial modification were most frequently studied issues aiming to improve the properties of short or long fiber reinforced composites. However, interfacial modification of natural fiber mat reinforced thermoplastics was rarely reported elsewhere and there is no report 
on surface modification of natural fiber mat using $\mathrm{NaOH}$ solution and MPP emulsion. Composite strength and stiffness generally increased as a consequence of the improved mechanical properties of the fibers by $\mathrm{NaOH}$ treatment under isometric conditions. Impact damping was distinctly affected by the shrinkage state of the fibers during the $\mathrm{NaOH}$ treatment because of its influence on yarn toughness [11]. Silane treatment of fibers led to increased tensile, flexural strength, and Young's modulus of composites by up to $30 \%$ [12]. MPP was widely used as a coupling agent to improve the adhesion between natural fiber and PP, and the effect of MPP and fiber length on the performance of a jute/PP composite system has been investigated. The influence of the fiber-matrix adhesion in jute fiber-reinforced polypropylene on the materials behavior under fatigue and impact loadings was investigated by some authors [15]. A novel hybrid coupling agent made from silane coupling agent and MPP were found to be a good adhesion promoter to improve natural fiber reinforced powder polypropylene composites [16].

This paper introduces a new treating method for jute fiber mat by using $\mathrm{NaOH}$ and MPP emulsion to enhance the properties of jute/PP composite. Interfacial shear strength (IFSS) values were measured using a microbond test. Surface characterization using Scanning Electron Microscopy (SEM) and Fourier Transform Infrared (FT-IR) spectroscopy was carried out to observe the modification on fiber surfaces after the treatment and the effect of $\mathrm{NaOH}$ treatment on jute fibers in terms of their diameter and mechanical strength is explained.

\section{Experimental}

\subsection{Materials}

Polypropylene (Y3700) with a melt flow index of $37 \mathrm{~g} / 10 \mathrm{~min}$ and density of $0.908 \mathrm{~g} / \mathrm{cm}^{3}$, supplied by Shanghai Jinshan petrochemical company was used in this work. MFI was measured under temperature of $230^{\circ} \mathrm{C}$. Polypropylene wax with an average molecular weight of 5000 8000 were obtained from Shanghai Jinshan Plastic company to prepare MPP emulsion. Jute fibers were obtained from Zhenjiang Lida Fiber Company. The fibers were washed with water and dried in an air oven at $70^{\circ} \mathrm{C}$ for $8 \mathrm{~h}$ and a vacuum oven at $60^{\circ} \mathrm{C}$ for $2 \mathrm{~h}$ before preparation of composites.

\subsection{Preparation of MPP water emulsion}

In preparation of MPP emulsion, PP wax and maleic anhydride (MAH) were selected as raw materials and Benzoyl Peroxide (BPO) as initiator. First, PP wax and was put in acetone solution. Stirring and heat were applied to ensure the melting of $\mathrm{PP}$ wax. After acetone was vaporized by increasing temperature to $120^{\circ} \mathrm{C}, \mathrm{BPO}$ and MAH mixture dissolved in xylene was added to PP wax melt continuously to initiate reaction. Graft reaction was carried out in xylene solution under reaction temperature of $144^{\circ} \mathrm{C}$. After reaction completed, xylene was vaporized and emulsification was carried out by using water and emulsification reagent in high shear dispersing emulsifier for about $2 \mathrm{~h}$. Sodium bicarbonate was also used to counteract some leftover MAH. The MAH content in grafted $\mathrm{PP}$ is $7 \%$, which is measured by using the method of chemical titration.

In chemical titration, the grafted PP was dissolved in xylene with additional heating and circumfluence for 8 hours. The superfluous $\mathrm{KOH}$-ethanol solution was added and the surplus solution was titrated by using acetic acid-xylene solution to determine MAH content in grafted PP. Following formula shows how to calculate MAH content.

$\mathrm{G}=[\mathrm{mol}$ consumption of $\mathrm{KOH} \times$ molecular weight of $\mathrm{MAH} /(2 \times$ sample weight $)] \times 100 \%$

\subsection{Preparation of PP/jute composites}

PP reinforced by non-woven jute fiber mat was manufactured using a film-stacking method. In this film-stacking method, 2 layers of pre-dried nonwoven jute mats in combination with 3 layers of PP films were stacked alternately, with fiber content of $38 \mathrm{wt} \%$. Impregnation of the non-woven mats was achieved by applying heat $\left(200^{\circ} \mathrm{C}\right)$ and pressure (5 MPa) in a continuous molding machine (manufactured by Polymer Processing Laboratory).

The laminates were prepared through the period of preheating, hot pressing and cooling continuously. They were then cut into certain shape and prepared to specimens for mechanical tests by using a milling machine. The size of the specimens was determined according to ASTM standards. 


\subsection{Chemical treatment}

\subsubsection{Alkali treatment}

$\mathrm{NaOH}$ which was used for treatment was provided by Shanghai Feida trading company. The fiber mats were put in a stainless steel vessel containing solution of $\mathrm{NaOH}$ with different concentration of $2 \mathrm{wt} \%$ and $5 \mathrm{wt} \%$ and a given pressure was applied to ensure good impregnation of $\mathrm{NaOH}$ solution. This was kept for $1 \mathrm{~h}$, after which the fiber mats were washed thoroughly with water to remove the excess of $\mathrm{NaOH}$ on the fibers. Final washing was carried out with distilled water and the fiber mats were finally air dried at $70^{\circ} \mathrm{C}$ for $8 \mathrm{~h}$ and vacuum dried at $60^{\circ} \mathrm{C}$ for $2 \mathrm{~h}$.

\subsubsection{Silane treatment}

The untreated fiber mats were placed in a stainless steel vessel containing solution of silane coupling agent (KH550) with concentration of $2 \mathrm{wt} \%$ for $1 \mathrm{~h}$. Chemical formula of KH550 is $\mathrm{NH}_{2}\left(\mathrm{CH}_{2}\right)_{3} \mathrm{Si}\left(\mathrm{OC}_{2} \mathrm{H}_{5}\right)_{3}$ supplied by Shanghai Yaohua industrial trading company. The hydrolysis takes place in water for about $1 \mathrm{~h}$. The mats were then dried in an air oven at $70^{\circ} \mathrm{C}$ for $8 \mathrm{~h}$ and then vacuum oven at $60^{\circ} \mathrm{C}$ for $2 \mathrm{~h}$.

\subsection{3. $\mathrm{NaOH}+\mathrm{MPP}$ emulsion treatment}

The jute fiber mat was first treated by $\mathrm{NaOH}$ under guideline of alkali treatment above and then was soaked in $2 \mathrm{wt} \%$ MPP water emulsion for $1 \mathrm{~h}$ to ensure MPP particles adhered on surface of the jute fibers. The mats were then dried in air and vacuum oven at $60^{\circ} \mathrm{C}$.

\subsection{Fiber surface characterization}

The surface topography of fibers was investigated using a scanning electron microscope (SEM), (SEM Model JSM-6360LV, JEOL Corporation Japan). The FTIR spectra of raw and surface treated natural fibers were recorded in a Nicolet AVATAR360 FT-IR spectrophotometer (Nicolet Corporation USA).

\subsection{Mechanical characterization}

The tensile properties, such as tensile strength, elongation at break, and tensile modulus of the composites were evaluated following the ASTM
D638 method with a crosshead speed of $2 \mathrm{~mm} / \mathrm{min}$. The ASTM D790 method was followed to evaluate the flexural properties and ASTM D256 method for evaluation of impact strength. All tests were carried out at room temperature $\left(20 \pm 2^{\circ} \mathrm{C}\right)$ and with a relative humidity between 25 and $50 \%$.

The tensile properties of jute fibers were measured using a single fiber tensile testing machine (Model YG004A, Changzhou No2 Weaving Machine Factory). Specimen gauge length was $20 \mathrm{~mm}$. One hundred fibers were tested in order to give the probability distribution of their tensile strength.

The interfacial shear strength (IFSS) of specimens was measured by a microbond technique [17]. All specimens were equilibrated at standard conditions of $21^{\circ} \mathrm{C}$ and $65 \%$ relative humidity for more than $24 \mathrm{~h}$ before the microbond test on a mechanical testing machine using an iron slice with a round aperture. The diameter of the aperture is larger than that of a fiber and smaller than the size of a micro droplet in order to pull out the fiber from micro droplet. The schematic of the microbond test rig is shown in Figure 1. The diameter, $d$, and embedded length, $l$, of the fiber were measured prior to the microbond test using an optic microscope and an image processing analysis program called UTHSCA Imagetool. As the fiber was pulled out, the shear load at the fiber/micro droplet interface increased. Debonding occurred when the load exceeded the interfacial bond strength. The average IFSS, $\tau$, was calculated using the Equation (1):

$$
\tau=\frac{F}{\pi \cdot d \cdot l}
$$

where $F$ is the load to debond the micro droplet. It was assumed that the shear strength was uniform along the entire fiber/micro droplet interface. Fifty

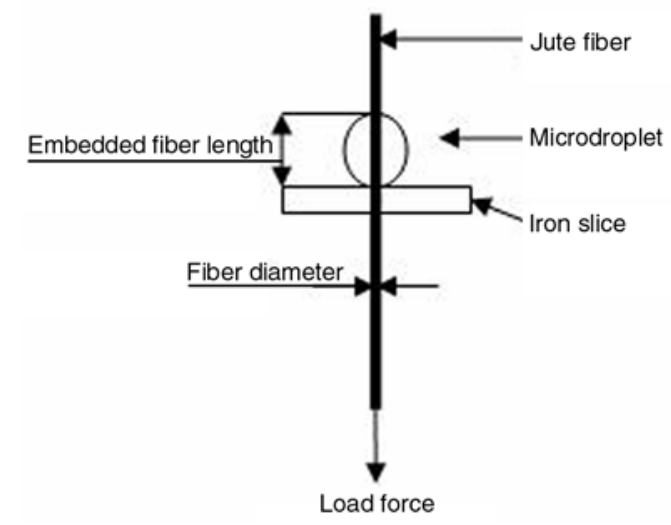

Figure 1. Schematic of the microbond test rig 
successful tests were conducted to obtain statistical results.

\section{Results and discussions}

\subsection{Fiber surface characterization}

The surface structures of untreated and alkali treated jute fibers are shown in Figure 2. From comparison of the SEM-micrographs, it seems that the untreated fibers had smooth surfaces (Figure 2a and $2 \mathrm{c}$ ), having some impurities and layers over layers of sheet substances like wax or fatty substances whereas the surfaces of the treated fibers were rough (Figure $2 b$ and $2 d$ ). It can also been seen that a number of lumpy strips existed on the surfaces of the treated fibers, which might be due to mercerization function of $\mathrm{NaOH}$, resulting in the partial removal of wax or fatty substances. It is a well-known fact [18] that there are binder lignin and fatty substances which hold the unit cells firmly in a fiber. After alkali treatment, the crystallinity of fibers increases [2], which might be attributed to the removal of the cementing materials, leading to a better packing of cellulose chains. Additionally, treatment of the fibers with $\mathrm{NaOH}$ might lead to a decrease in the spiral angle and increase in molecule orientation.

Untreated and treated jute fibers were analyzed by FTIR spectroscopy using attenuated total reflectance (ATR) scanning with a resolution of $2 \mathrm{~cm}^{-1}$ and a scanning range from $4000 \mathrm{~cm}^{-1}$ to $450 \mathrm{~cm}^{-1}$. The FTIR spectra of untreated and

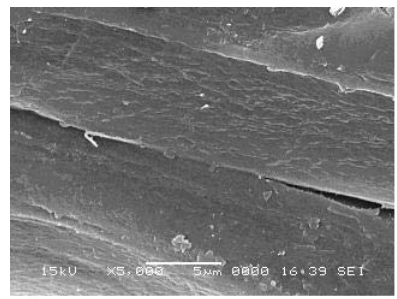

a)

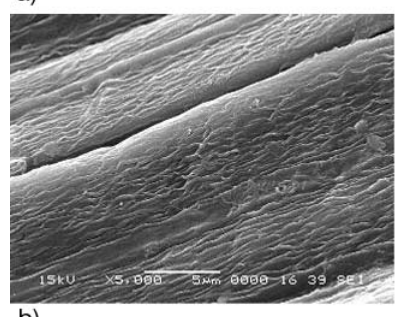

b)

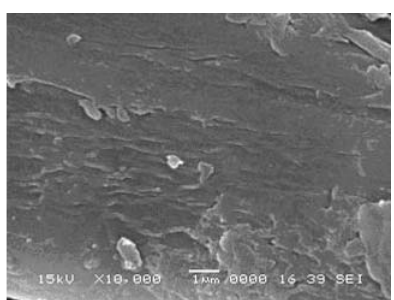

c)

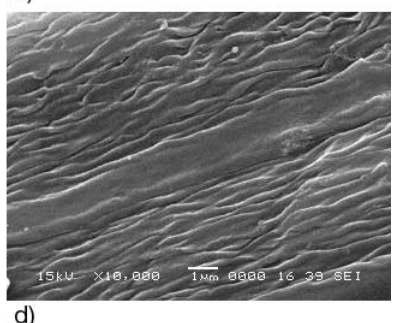

Figure 2. SEM micrographs of: (a) untreated jute (5000x); (b) $5 \% \mathrm{NaOH}$ treated jute $(5000 \times)$; (c) untreated jute $(10000 \times)$; and (d) $5 \% \mathrm{NaOH}$ treated jute $(10000 \times)$

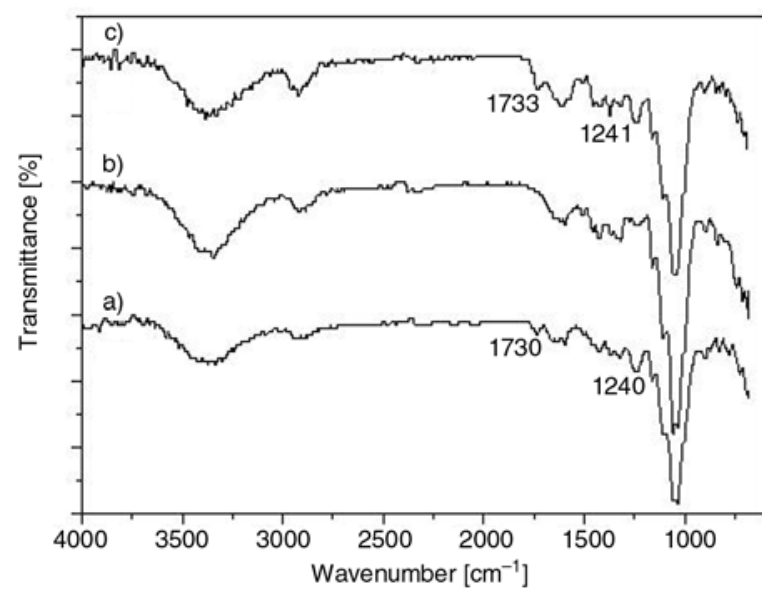

Figure 3. FTIR spectra of: (a) untreated jute; (b) alkali treated jute; and (c) alkali and MPP emulsion treated jute fibers

treated jute fibers are shown in Figure 3. $\mathrm{NaOH}$ and MPP emulsion treated jute fiber was heated to $160^{\circ} \mathrm{C}$ before characterization in order to initiate the reaction between jute and MPP wax. It can be noted that there is an absorption band at $\sim 1730 \mathrm{~cm}^{-1}$ and $1240 \mathrm{~cm}^{-1}$ for the untreated jute fibers, which no longer exists for $\mathrm{NaOH}$ treated fibers. The hemicelluloses contain groups that absorb in the carbonyl region and ester group on surface of the fiber. They are soluble in aqueous alkaline solutions. During alkali treatment, a substantial portion of uronic acid and fatty substances might be removed resulting in disappearance of this peak at $\sim 1730 \mathrm{~cm}^{-1}$ and $1240 \mathrm{~cm}^{-1}$. After treating with alkali and MPP emulsion, the peak at $\sim 1733 \mathrm{~cm}^{-1}$ and $1241 \mathrm{~cm}^{-1}$ appears again, which is consistent with the work reported by Mohanty et al. [19]. This may be attributed to presence of ester functionality in the MPP treated jute fibers due to carbonyl functionality in MPP. The schematic representation of the possible reaction of MPP with jute fiber is represented in Figure 4.

\subsection{Distribution characterization of jute fiber}

Figure 5 shows the cumulative diameter distribution of the untreated jute fibers and treated jute fibers including $2 \mathrm{wt} \% \mathrm{KH} 550$ treated, $2 \mathrm{wt} \%$ $\mathrm{NaOH}$ treated and $5 \mathrm{wt} \% \mathrm{NaOH}$ treated, respectively. In each kind of fiber, 100 fiber samples were selected to conduct the experiment. The experimental diameter data were estimated from $F(N)=$ $i /(N+1)$, where $N$ is the total number of samples tested and $i$ is the number in ascendingly ordered 


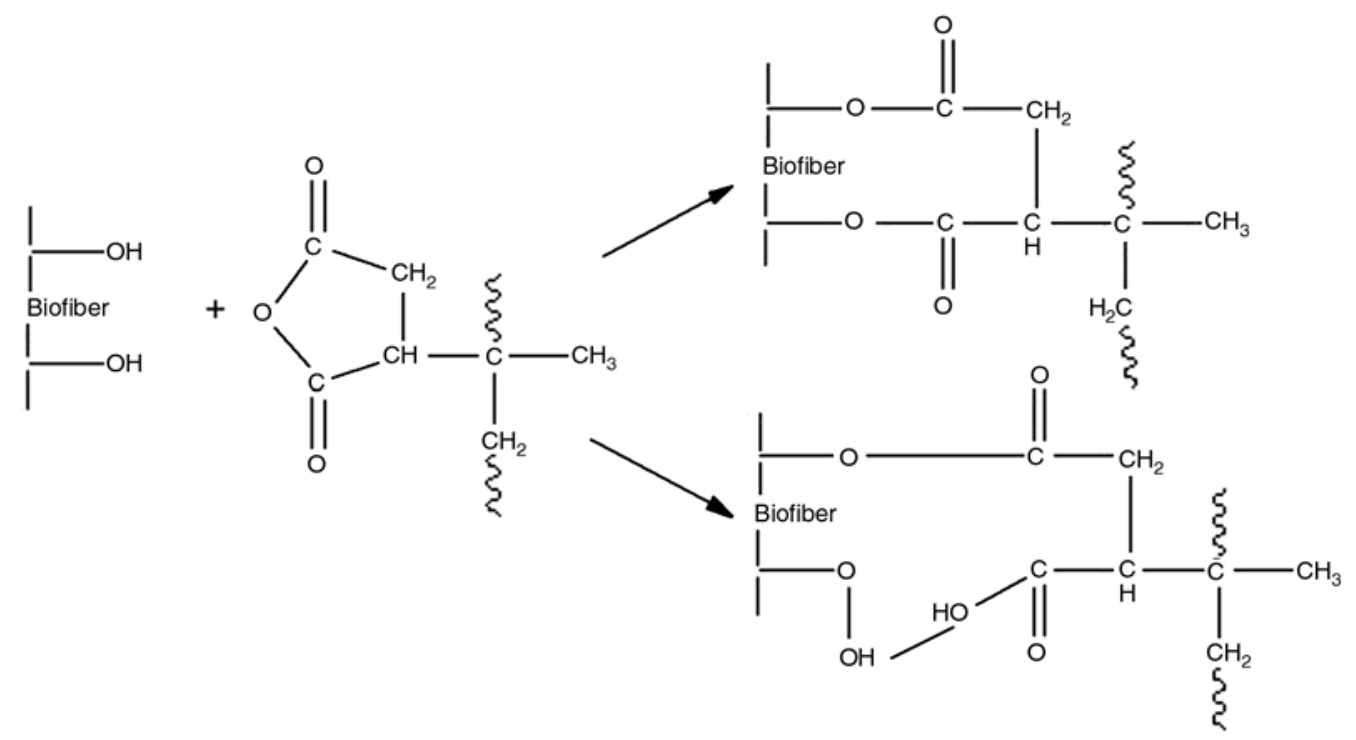

Figure 4. Possible reaction of natural/biofiber with MPP

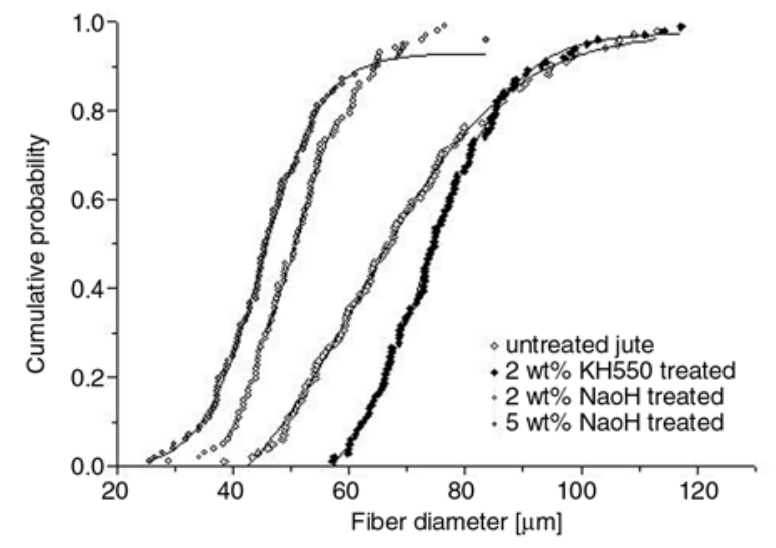

Figure 5. Diameter distribution of untreated and treated jute fiber

diameter data. It was easily noted that the distribution of the diameter shifted significantly to the left side under the treatment with $\mathrm{NaOH}$ and to the right side under the treatment with KH550. The average diameter of the untreated fibers is $62 \mu \mathrm{m}$ whilst that of the fibers treated by $2 \mathrm{wt} \%, 5 \mathrm{wt} \% \mathrm{NaOH}$ and $2 \mathrm{wt} \% \mathrm{KH} 550$ is $51 \mu \mathrm{m}, 47 \mu \mathrm{m}$ and $72 \mu \mathrm{m}$, respectively. The bigger diameter of untreated jute fibers resulted from layers of wax and fatty substances on their surface and a large numbers of micro fibrils in one fiber bundle. The reduced diameter of $\mathrm{NaOH}$ treated jute fibers can be attributed to removal of plentiful wax and fatty substances and cementing materials in fiber bundles while the increased diameter of KH550 treated jute fibers can be attributed to reaction between jute fiber and coupling agent taking place on the surface of the fibers.

The fiber strength values were further analyzed statistically using a two-parameter Weibull distribu- tion to describe the fiber strength distribution. The statistical variability of the tensile strength of jute fibers can be written as Equation (2):

$$
P=1-\exp \left[-L\left(\sigma-\frac{\sigma_{u}}{\sigma_{0}}\right)^{w}\right]
$$

where $P$ is the cumulative probability of failure of a fiber length of $L$ at an applied stress $\sigma, \sigma_{0}$ is the characteristic strength of a unit which is also called Weibull scale parameter, and $\sigma_{u}$ is the lowest value of the strength and is set to zero for simplification. Hence the two-parameter Weibull equation can be re-written as Equation (3):

$P=1-\exp \left[-1\left(\frac{\sigma}{\sigma_{0}}\right)^{w}\right]$

where $w$ is the shape parameter or Weibull modulus which defines the variability in the strength values. A low value of the Weibull modulus indicates a high variability. Rearrangement of the two-parameter Weibull equation shown leads to the Equation (4):

$\ln \left[\ln \frac{1}{1-P}\right]=w \ln \sigma-w \ln \sigma_{0}+\ln L$

where $w$ and $\sigma_{0}$ can be found from the slope and intercept of the plot $\ln [\ln 1 /(1-P)]$ versus $\ln \sigma$. The Weibull plots for untreated and treated jute fibers are shown in Figure 6a. A good fit was observed with this distribution, as it was evident from the 
Table 1. Tensile strength of jute fibers and Weibull parameter

\begin{tabular}{|l|c|c|c|}
\hline \multicolumn{1}{|c|}{ Jute fibers } & Tensile strength \pm SD $^{*}[\mathbf{M P a}]$ & Weibull modulus & Characteristic strength [MPa] \\
\hline Untreated & $250 \pm 119$ & 2.2 & 238 \\
\hline $2 \mathrm{wt} \% \mathrm{NaOH}$ treated & $325 \pm 132$ & 2.6 & 304 \\
\hline $5 \mathrm{wt} \% \mathrm{NaOH}$ treated & $389 \pm 150$ & 2.7 & 355 \\
\hline $2 \mathrm{wt} \% \mathrm{KH} 550$ treated & $326 \pm 145$ & 2.5 & 301 \\
\hline
\end{tabular}

*SD, standard deviation

closeness to the best-fit line. Weibull parameter obtained from the Weibull plots are given in Table 1 . It can be easily noted that before the treatment, Weibull modulus for jute fiber is 2.2 while after being treated with $2 \mathrm{wt} \% \mathrm{KH} 550,2 \mathrm{wt} \%$ $\mathrm{NaOH}$ and $5 \mathrm{wt} \% \mathrm{NaOH}$, the Weibull modulus are 2.5, 2.6 and 2.7 respectively, indicating a obvious variability in strength of untreated fibers compared to chemically treated fibers. It can be also seen that the Weibull modulus values for jute fibers are much lower compared to synthetic fiber such as carbon fiber [20], which indicates the non-homogeneous nature of natural fibers which in turn is due to the predominance of defects within their structures. Similar results were reported earlier for other
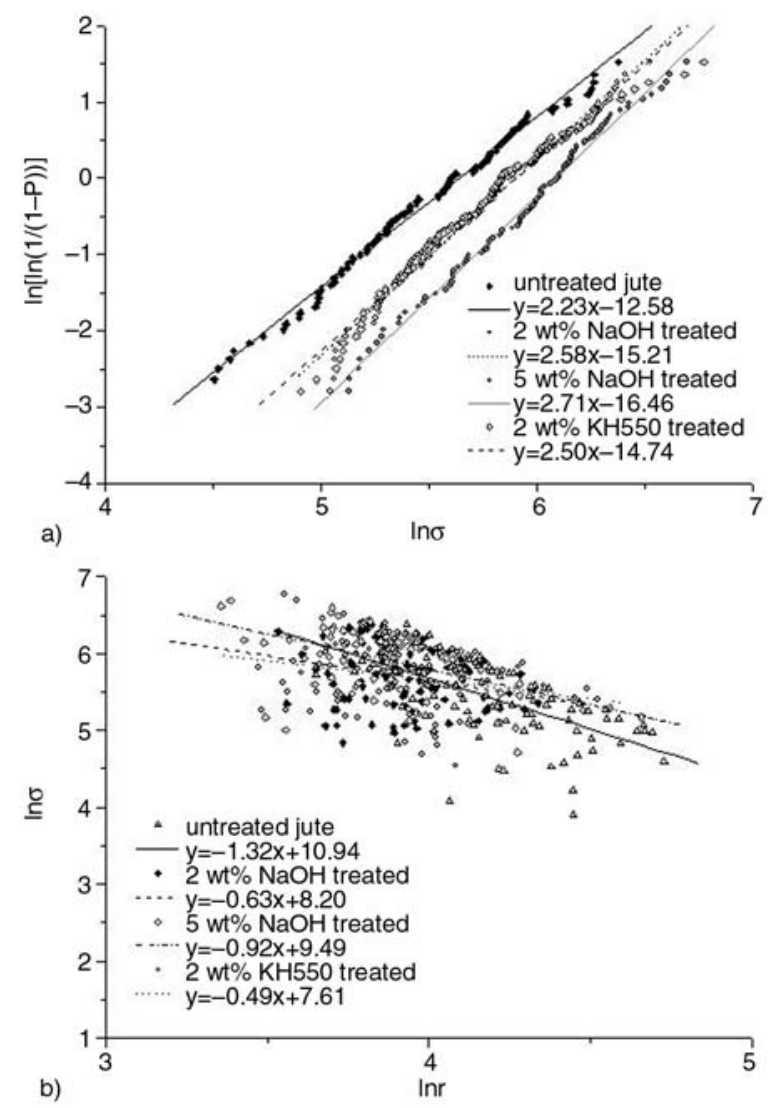

Figure 6. (a) Weibull plots for untreated and differently treated jute fibers. (b) Variation of tensile strength of jute fibers as a function of fiber diameter natural fibers by some authors [21-23]. The tensile strength of fibers increases obviously after treatment of $\mathrm{NaOH}$. Generally speaking, a fiber with larger cross-section area should have greater chance to have a bigger flaw. Therefore, it is expected to be weaker than that with a smaller cross-section area. The cross-section area of jute fibers decreases after they were treated by $\mathrm{NaOH}$, which could be concluded from the diameter change of jute fibers. This can also be proved by Weibull plots in Figure 6a, where the curve shifts right after treatment. In Figure $6 \mathrm{~b}$, fiber strength exhibited a scattering with various diameters for different kind of fibers. Scattering in strength of natural fibers may be influenced by inhomogeneous distribution of their chemical structure and inherent properties of composite materials.

\subsection{Mechanical and micromechanical properties of the composites}

The mechanical properties including flexural strength, tensile strength and impact strength in association with interfacial shear strength of jute fiber/PP composites formed with different treating methods is shown in Table 2.

The mean IFSS between untreated jute fiber and PP is $3.49 \mathrm{MPa}$, which is much lower than the IFSS between synthetic fiber and thermosets [24]. The IFSS depends mainly on two factors: mechanical interlocking and chemical bonding. In the case of untreated jute fiber/PP, chemical bonding is considered to be rather weak because of incompatibility between hydrophobic resin and - $\mathrm{OH}$ group on the fiber. As a result, the IFSS is mainly attributed to the high surface irregularity of jute fibers and the resulting mechanical interaction.

After treating with alkali solution, the possible reaction between $-\mathrm{OH}$ groups on the fiber and $\mathrm{NaOH}$ might greatly diminish water absorption of the fiber, which improved the compatibility between fibers and resin. The IFSS with $2 \mathrm{wt} \%$ $\mathrm{NaOH}, 5 \mathrm{wt} \% \mathrm{NaOH}$ and $2 \mathrm{wt} \% \mathrm{KH} 550$ treatment 
Table 2. IFSS and mechanical properties of jute fiber mat reinforced PP

\begin{tabular}{|c|c|c|c|c|}
\hline Jute fibers & $\begin{array}{c}\text { IFSS } \pm \text { SD } \\
{[\mathrm{MPa}]}\end{array}$ & $\begin{array}{c}\text { Flexural strength } \pm \text { SD } \\
{[\mathrm{MPa}]}\end{array}$ & $\begin{array}{c}\text { Tensile strength } \pm \text { SD } \\
{[\mathrm{MPa}]}\end{array}$ & $\begin{array}{c}\text { Impact strength } \pm \text { SD } \\
{\left[\mathrm{J} \mathrm{m}^{-1}\right]}\end{array}$ \\
\hline untreated & $3.49 \pm 0.32$ & $35.1 \pm 1.2$ & $28.4 \pm 0.9$ & $65.0 \pm 3.2$ \\
\hline 2 wt $\%$ KH550treated & $4.27 \pm 0.83$ & $43.8 \pm 1.7$ & $33.7 \pm 1.4$ & $62.8 \pm 3.1$ \\
\hline $5 \mathrm{wt} \% \mathrm{NaOH}$ treated & $4.85 \pm 0.64$ & $55.2 \pm 2.2$ & $38.1 \pm 1.6$ & $57.4 \pm 2.9$ \\
\hline $2 \mathrm{wt} \% \mathrm{NaOH}$ treated & $5.27 \pm 0.82$ & $58.3 \pm 2.3$ & $36.9 \pm 1.5$ & $61.2 \pm 3.3$ \\
\hline $2 \mathrm{wt} \% \mathrm{NaOH}+\mathrm{MPP}$ emulsion & $9.00 \pm 1.47$ & $59.0 \pm 2.0$ & $42.2 \pm 2.3$ & $54.1 \pm 2.5$ \\
\hline
\end{tabular}

are approximately $51 \%, 39 \%$ and $22 \%$ greater than that of the untreated fibers. It should be noted that coupling agents can play a role of bridging between fibers and resins. After treating with $\mathrm{NaOH}$ and MPP emulsion, the IFSS increased dramatically to 9.00 MPa. In this case, the effect of chemical bonding on the IFSS might be significant as reaction could occur between fiber and coupling agents.

The level of adhesion between fiber and matrix greatly affects the mechanical properties of the composites. The flexural strength of the untreated composite increases correspondingly with the treatment by $\mathrm{KH} 550, \mathrm{NaOH}$ and $\mathrm{NaOH}+\mathrm{MPP}$ emulsion. Similarly, the tensile strength of the untreated fibers also increases simultaneously. However, the impact strength seemed to decrease slightly after each treatment. These results indicate that surface modification improved the interfacial adhesion between fibers and matrix, resulting in the higher flexural strength and tensile strength as well as the modulus but slightly lower impact strength. In other words, the rigidity of the fibers after the treatments increased but their toughness reduced. The reason why mechanical properties of jute fiber reinforced PP are improved may be different in terms of different treatment. In alkali treatment, reaction between jute fiber and $\mathrm{NaOH}$ can be shown in following ways:

\section{Cell-OH $+\mathrm{NaOH} \rightarrow$ Cell- $-\mathrm{O}^{-} \mathrm{Na}^{+}+\mathrm{H}_{2} \mathrm{O}+$ impurity}

Natural fiber is hydrophilic due to large number of hydroxyl groups in their structure, which makes it incompatible with PP that is hydrophobic. In this reaction, a number of hydroxyl groups can be eliminated, which decreases the tendency of water absorption and improves the compatibility between jute fiber and PP. Besides, the mechanical properties of jute fiber are improved through alkali treatment, which has been proved above. Since the mechanical properties of the reinforcing materials play an important role in composite properties,
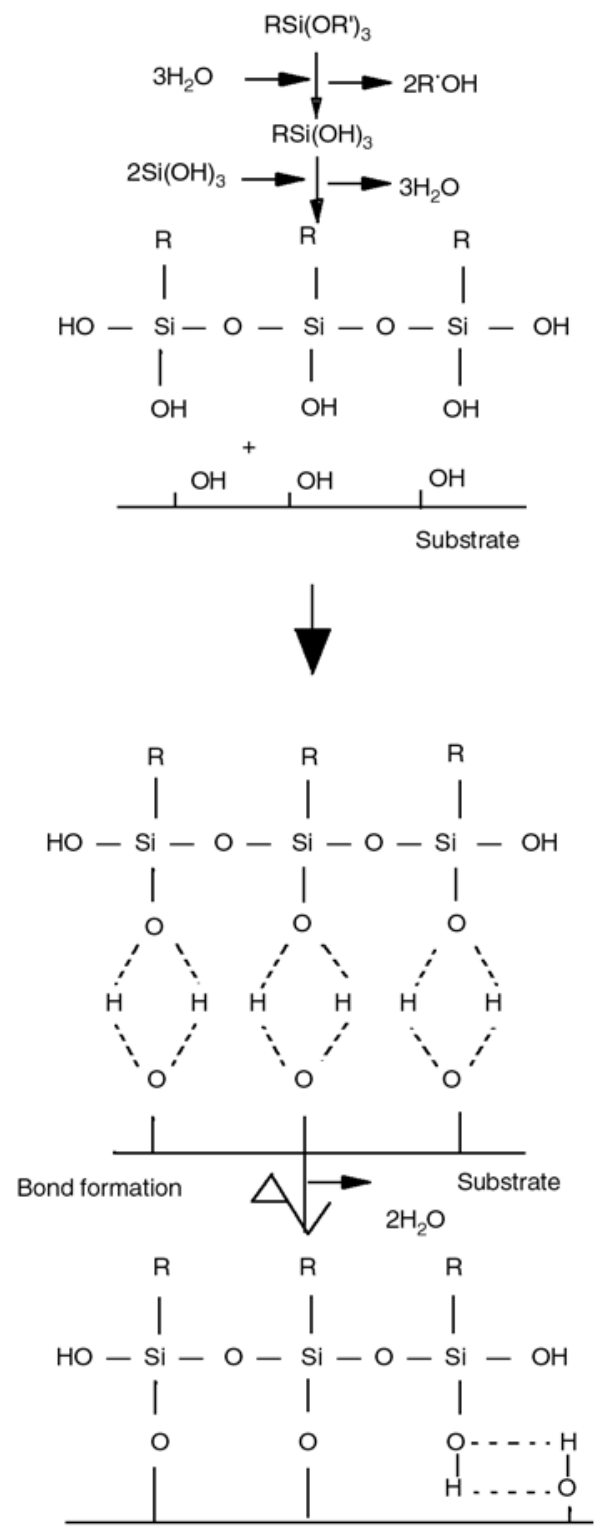

Figure 7. Scheme of reaction between coupling agent and jute fiber

increasing tensile strength of jute fiber contributes to the improvement of mechanical properties of the composite. As to KH550 and MPP, they play a role like a bridge between jute fiber and PP. The reaction between coupling agent and jute fiber can be displayed in Figure 7, where hydrogen bond is 
formed. Thus the adhesion between jute fiber and PP is improved, which can contribute to the improving properties of the composite. In reaction between jute fiber and MPP, both chemical (ester bond) and physical interactions (hydrogen bond) are formed. The PP chain of MPP diffuses into the PP matrix through interchain entanglement. The kind of entanglement should be stronger than most of MPP because we applied MPP particles on the surface of the jute fiber through coating of MPP water emulsion and this kind of MPP has a much smaller molecular weight and much higher content of MAH. On the other hand, the maleic anhydride group forms both covalent and hydrogen bonds with the hydroxyl groups of the fiber. These cause better adhesion between the fiber and the matrix. Therefore, the transfer of stress from the matrix to the fibers is improved and lead to highest flexural and tensile properties of $\mathrm{PP}$ reinforced with $\mathrm{NaOH}$ and MPP emulsion treated jute fiber from among all composites.

The reason why IFSS is in inverse ratio with impact strength of the composites may be speculated as follows: Firstly, the interfacial adhesion is weak before surface modification, which results in a number of voids around fiber surfaces that can be seen from Figure 8 . The main reason might be huge difference of surface energy between untreated fiber and matrix. When PP melt reaches fiber surface, some small defects on fiber surface can't be surrounded by matrix, which leads to formation of voids. After an impact force is applied to the composite, the stress is transferred from the matrix to the fiber surfaces, which causes these voids to become a number of micro crackles. Then absorption of a significant amount of energy by these crackles takes place around the interface of the composites, which consequently exhibits relatively higher impact strength. Although adhesion between fibers and matrix could be greatly strengthened after the fibers are treated, the decrease in size of the pores leads to formation of fewer micro crack-

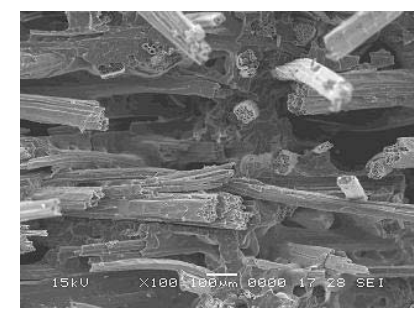

Figure 8. Cross section of untreated jute reinforced PP les. Under these circumstances, an impact force could cause the composite to crumble as few energy is absorbed by the micro crackles. Moreover, significant stress concentration might exist at the end of a fiber, where the stress concentration could not be dissipated in this area due to its strong adhesion with matrix. With decline of the IFSS, slipping on the interface was possible, which could consume energy and prevent stress concentration. Thus, the impact strength is improved and the elongation of the material is increased at the same time. It is worth mentioning that the composite with balanced rigidity and toughness or with different combination of mechanical properties could be tailor-made, which remains to be proved in future works.

\section{Conclusions}

Treatment of jute fibers with alkali treatment and MPP emulsion has been found to be very efficient in improving the fiber-matrix adhesion in jute fiber mat reinforced PP composites. $\mathrm{NaOH}$ treatment removed wax and fatty substances and changed surface topography of the jute fibers through SEM observations and FT-IR spectra. Consequently, the diameter distribution for the fibers changed dramatically after treatment with coupling agent or $\mathrm{NaOH}$. The distribution of strength for untreated and treated jute fiber fits well with Weibull distribution and difference of fiber strength can be explained by Weibull modulus and characteristic strength. There was a strong connection between the interfacial shear strength and the mechanical properties of the jute/PP composites, including flexural strength, tensile strength and impact strength, and the results also showed that combination of $\mathrm{NaOH}$ and MPP emulsion is a good adhesion promoter in manufacturing jute fiber mat reinforced PP and controlling interfacial shear strength can be an effective strategy to balance the mechanical properties of the composites.

\section{References}

[1] Saheb D. N., Jog J. P.: Natural fiber polymer composites: A review. Advances in Polymer Technology, 18, 351-363 (1999).

[2] Bledzki A. K., Gassan J.: Composites reinforced with cellulose based fibres. Progress in Polymer Science, 24, 221-274 (1999). 
[3] Eichhorn S. J., Baillie C. A., Zafeiropoulos N., Mwaikambo L. Y., Ansell M. P., Dufresne A., Entwistle K. M., Herrera-Franco P. J., Escamilla G. C., Groom L., Hughes M., Hill C., Rials T. G., Wild P. M.: Current international research into cellulosic fibres and composites. Journal of Materials Science, 36, 2107-2131 (2001).

[4] Srikanth G., Nangia S.: Development of natural fiber composites in India. in 'Proceedings of Annual Convention and Trade Show, Tampa, USA' 3-6 (2001).

[5] Eastham J.: Natural fibres for the automotive industry in 'Seminar of The Alternative Crops Technology Interaction Network, Manchester, UK' 16, 142-146 (2001).

[6] Han S. O., Defoort B., Drzal L. T., Askeland P. A.: Environmentally friendly biocomposites for automotive applications in ' $33^{\text {rd }}$ ISTC Conference, Seattle, USA' 33, 1466-1477 (2001).

[7] Marsh G.: Next step for automotive materials. Materials Today, 6, 36-43 (2003).

[8] Chen Y., Chiparus O., Sun L., Negulescu I., Parikh D. V., Calamari T. A.: Natural fibers for automotive nonwoven composites. Journal of Industrial Textiles, 35, 47-62 (2005).

[9] Head P. R.: Construction materials and technology: A look at the future. Proceedings of the Institution of Civil Engineers: Civil Engineering, 144, 113-118 (2001).

[10] Bledzki A. K.: New light construction materials. Przemysl Chemiczny, 82, 548-548 (2003).

[11] Gassan J., Bledzki A. K.: Possibilities for improving the mechanical properties of jute/epoxy composites by alkali treatment of fibres. Composites Science and Technology, 59, 1303-1309 (1999).

[12] Gassan J., Bledzki A. K.: Effect of cyclic moisture absorption desorption on the mechanical properties of silanized jute-epoxy composites. Polymer Composites, 20, 604-611 (1999).

[13] Gassan J., Gutowski V. S.: Effects of corona discharge and UV treatment on the properties of jute-fibre epoxy composites. Composites Science and Technology, 60, 2857-2863 (2000).

[14] Karmaker A. C., Youngquist J. A.: Injection moulding of polypropylene reinforced with short jute fibers. Journal of Applied Polymer Science, 62, 1147-1151 (1996).
[15] Gassan J., Bledzki A. K.: Possibilities to improve the properties of natural fiber reinforced plastics by fiber modification - jute polypropylene composites. Applied Composite Materials, 7, 373-385 (2000).

[16] Mohanty A. K., Drzal L. T., Misra M.: Novel hybrid coupling agent as an adhesion promoter in natural fiber reinforced powder polypropylene composites. Journal of Materials Science Letters, 21, 1885-1888 (2002).

[17] Miller B., Muri P., Rebenfeld L.: A microbond method for determination of the shear strength of a fiber/resin interface. Composites Science and Technology, 28, 17-32 (1987).

[18] Bismarck A., K. Monhanty A., Aranberri-Askargorta I., Czapla S., Misra M., Hinrichsen G., Springer J.: Surface characterization of natural fibers; surface properties and the water up-take behavior of modified sisal and coir fibers. Green Chemistry, 3, 100-107 (2001).

[19] Mohanty A. K., Drzal L. T., Misra M.: Engineered natural fiber reinforced polypropylene composites: Influence of surface modifications and novel powder impregnation processing. Journal of Adhesion Science and Technology, 16, 999-1015 (2002).

[20] Pickering K. L., Murray T. L.: Weak link scaling analysis of high-strength carbon fibre. Composites Part A: Applied Science and Manufacturing, 30, 1017-1021 (1999).

[21] Panthapulakkal S., Zereshkian A., Sain M.: Preparation and characterization of wheat straw fibers for reinforcing application in injection molded thermoplastic composites. Bioresource Technology, 97, 265-272 (2006).

[22] Doan T-T-L., Gao S-L., Mader E.: Jute/polypropylene composites I. Effect of matrix modification. Composites Science and Technology, 66, 952-963 (2006).

[23] Park J.-M., Quang S. T., Hwang B-S., DeVries K. L.: Interfacial evaluation of modified jute and hemp fibers/polypropylene (PP)-maleic anhydride polypropylene copolymers (PP-MAPP) composites using micromechanical technique and nondestructive acoustic emission. Composites Science and Technology, 66, 2686-2699 (2006).

[24] Pisanova E., Zhandarov S., Mader E., Ahmad I., Young R. J.: Three techniques of interfacial bond strength estimation from direct observation of crack initiation and propagation in polymer-fibre systems. Composites: Part A-Applied Science and Manufacturing, 32, 435-443 (2001). 